\title{
A New Approach to Ideological and Political Education in Higher Vocational Education under the Environment of Network Media
}

\author{
Zhou Xiaoyan \\ Jiangsu Shipping College, Nantong City, Jiangshu Province, 226010, China
}

\begin{abstract}
The development of economy also makes the network popular, although the network provides a rich way for life and education, but also adds some challenges.Nowadays, under the environment of network media, we must deepen ideological and political education, guide the thought of higher vocational students and make them accept correct values, which can not only reduce the influence of network bad information, but also make higher vocational students have relatively healthy ideas. In order to show the effectiveness of ideological and political.
\end{abstract}

Keywords: network media; higher vocational education; ideological and political education

\section{Introduction}

The network media belongs to the school public opinion propaganda, the information transmission main tool, simultaneously gives the public opinion support for the ideological and political education, provides the corresponding interactive platform.Now "00s generation" has gradually become the main body of higher vocational students, because their growth background is obviously different, so that their value orientation or ideas have new characteristics.In this environment, it is more and more important to make ideological and political education more important. Therefore, higher vocational colleges should make good use of network media, integrate it with the science of ideological and political education, and improve the educational effect.

https://doi.org/10.47852/bonviewCETR2020010205

This is an open access article published by the BON VIEW PUBLISHING PTE. under the Creative Commons Attributions License. 
I. The Necessity of Ideological and Political Education in Higher Vocational Education in Network Media Environment

First of all, it can enrich teaching resources. From the point of view of ideological and political education in the past, information resources usually use traditional carriers to introduce higher vocational classrooms, which not only makes the renewal of ideological and political resources relatively slow, but also lacks timeliness. As we all know, ideological and political education has obvious timeliness.As a result, the slow updating of resources may be improved by using network media. On the one hand, network media has many resources, which can update the content of ideological and political education in real time, keep up with current affairs and frontier hot spots. On the other hand, can $^{[1]}$ with vocational students' hobbies or psychological characteristics.For example, higher vocational students may watch Weibo every day and browse hot information, so in teaching, ideological and political teachers can introduce relevant hot events as cases. This can not only integrate ideological and political thoughts and hot events organically, deepen students' understanding of ideological and political thoughts, but also make them produce enthusiasm for ideological and political study, perfect their own behavior and perfect their personal character.

Secondly, we can innovate teaching methods. To some extent, the network media is the scientific reform of ideological and political education before, because the network media breaks through the limitation of time and space, at the same time, it also makes the one-way education mode end, and makes the quality of ideological and political education improve obviously.As we all know, there are many elements such as words and sounds in the network media, and teachers can use PPT or other teaching courseware to teach in ideological and political education.This can not only serve as a new auxiliary tool, provide good teaching assistance to ideological and political education, but also make ideological and political education radiate new charm and make it no longer boring.At the present stage, the network education work has been carried out one after another, which makes the information resources begin to be integrated into the teaching. Therefore, the network media will gradually appear in the ideological and political education, sublimate the ideological connotation of higher vocational students, and make the ideological and political education more influential.In addition, under the network media, let the teacher-student communication become more equal, not only increases the thought collision related opportunity.For example, to discuss a hot event, to publish personal thoughts or ideas, and to use the network platform can also promote ideological and political teachers to grasp the dynamic and scientific grasp of the relevant ideas of higher vocational students.For example, when it is found that higher vocational students have unhealthy ideological patterns or ideas, they should be corrected to avoid their unhealthy behavior and improve their thinking.

II. New Approach of Ideological and Political Education in Higher Vocational Education under 


\section{the Environment of Network Media}

A. Changing Educational Ideas

In the information age, the network media is well developed, in this environment, if we want to improve the ideological and political work, we must reshape the educational concept.By breaking the unsuitable idea of ideological and political education in the past and innovating the idea of ideological and political education in combination with the current culture or the characteristics of the times, it can not only realize the organic integration of social value and personal value, but also deepen the ${ }^{[2]}$ of higher vocational education. Improve the effect of ideological and political education.At this stage, the network culture is more and more in-depth, therefore, how to make some social interests and students' personal interests in the network to balance each other, become the ideological and political education attention and discussion issues.At present, young Internet users in China occupy the main position, among which higher vocational students can not be ignored. On the one hand, network culture has strong interactivity and openness, and it is easy for higher vocational students to contact different information.On the other hand, it also makes the values of higher vocational students easy to change, which makes higher vocational students increasingly influenced by network related culture, pays attention to personal value, pursues personality development, and thus neglects social value.Under this background, ideological guidance is particularly important. Through ideological and political education, it can not only impart social value, let higher vocational students respect social interests, but also respect the personality thought of higher vocational students and make them accept systematic value thought. Avoid one-sided value and affect physical and mental health.In recent years, group incidents often occur on the network. Therefore, schools should alert the negative effects of the network, strengthen the systematic identification of network information, correctly judge it, and pay attention to the relevant students in the post practice. Do a good job in their ideological and political work.In addition, to improve the level of ideological and political education, we need to start from the network environment, collect teaching materials, such as pictures or text.It can not only arouse the attention of higher vocational students, make them interested in ideological and political learning, but also enrich the relevant contents of ideological and political affairs and realize the improvement of teaching effect.

B. Innovative education model

Under the new situation, the mode of ideological and political education should be innovated to meet the characteristics of network education, so as to adapt to the network media environment and improve the teaching effect.

First, apply multimedia.From the point of view of the present stage of education, multimedia has gradually entered the school, in which multimedia belongs to the modern product, which needs to affirm its application value and attach importance to multimedia, so as to improve the way of 
ideological and political education. The biggest characteristic of multimedia can integrate pictures and even audio, enrich ideological and political education, not only can the ideological and political views be organically displayed in concrete forms, but also can make abstract ideas more vivid and make higher vocational students have good interest.For example, teachers should collect some hot topics for discussion in ideological and political classes. For example, in recent years ," whether or not the elderly should fall down on the road "has aroused widespread discussion, among which teachers can play the sketch" whether to help ".Then let the students begin to discuss the problem of "helping or not helping ", so that discussing each other, they can not only infiltrate certain traditional morality, strengthen the moral cultivation of higher vocational students, but also innovate the form of ideological and political education and make teaching effective.Secondly, build ideological and political education integration base. Ideological and political education was carried out in the past, ignoring the ${ }^{[3]}$ of post practice students, but in the new period, we should also pay attention to the post practice students.In general, the higher vocational students will practice in the last year to the front line of the enterprise. In the face of and unfamiliar environment, it is easy for students to be influenced by some thoughts. Therefore, the school must have an accurate orientation to the ideological and political education, set up the ideological and political system in accordance with the different stages of higher vocational students, maximize the training of skilled personnel, while improving their professionalism, so that they have healthy thinking.In addition, for those internship students, they gradually divorced from the higher vocational school environment, so the traditional ideological and political model can no longer meet the needs of internship students. Based on this, the network technology should be applied and ideological and political education should be carried out by remote way to meet the requirements of ideological and political education.

\section{Establishment of network guidance system}

In the network environment, there will be a lot of information, some of which are healthy, others are radical, so the school should set up a network guidance system, and the campus network public opinion to achieve scientific analysis. This can not only enhance the higher vocational students' understanding of the network public opinion, improve the discrimination, but also integrate the network information, make it become the material of ideological and political education, and improve the educational effect.

This can not only enhance the higher vocational students' understanding of the network public opinion, improve the discrimination, but also integrate the network information, make it become the material of ideological and political education, and improve the educational effect.Allow the ideological and political departments and counselors to cooperate and establish a collection mechanism, which can not only clarify the responsibilities of public opinion guidance, but also respect the opinions of higher 
vocational students ${ }^{[4]}$ timely discovery of real-time solutions, and strengthen ideological guidance. Allow the ideological and political departments and counselors to cooperate and establish a collection mechanism, which can not only clarify the responsibilities of public opinion guidance, but also respect the opinions of higher vocational students, ${ }^{[4]}$ timely discovery of real-time solutions, and strengthen ideological guidance.Although the minds of higher vocational students are slowly maturing, some events are prone to extreme or vulnerable to public opinion, so psychological fluctuations are great. In the face of this situation, the information screening mechanism is particularly important. Ideological and political teachers or network information department teachers identify different information, eliminate bad information, reduce students' influence and strengthen ideological character.Although the minds of higher vocational students are slowly maturing, some events are prone to extreme or vulnerable to public opinion, so psychological fluctuations are great. In the face of this situation, the information screening mechanism is particularly important. Ideological and political teachers or network information department teachers identify different information, eliminate bad information, reduce students' influence and strengthen ideological character.Therefore, there should be a relevant public opinion handling mechanism to enhance the effective early warning of network public opinion, which can not only give the fastest understanding of the events, but also achieve efficient solutions to the events, and reduce the impact of network public opinion on our school. In order to promote ideological and political education in an orderly manner.

D. Improving the effectiveness of education

Before the ideological and political education rarely considered the effectiveness, mostly referred to the ideological and political teaching materials for teaching, and some content or cases too long, can not have effectiveness, but also affect the students' systematic understanding of ideas.However, in the network environment, we should pay attention to the effectiveness of ideological and political education, give play to the value of network media, let students understand the diversified views and expand their knowledge.At this stage, higher vocational students can also understand the world without going out, especially paying attention to campus or social hot issues. Therefore, ideological and political teachers should also master the latest hot spots scientifically and organize them into educational materials for students to watch in ideological and political classes.It can not only close the distance from ideological and political education, avoid the high and low degree of ideological and political education, but also show the enthusiasm of higher vocational students and let them learn new ideas with the help of network media.For example ," People's Daily "APP not only condenses social hot spots, but also comments on hot spots and writes related articles, which are rich in new ideas and 
are of great help to ideological and political education. Therefore, teachers should lead higher vocational students to read, on the one hand, they can accumulate or learn writing techniques, on the other hand, they can be influenced by the values in the article and perfect their personal thoughts.In addition, the campus network site should be built and the network construction should be done well. Only by carrying out scientific management of the campus network can we ensure the normal operation of the campus network and prepare for the ideological and political education in advance.During this period, we should deepen the construction of network teachers. On the one hand, we should make teachers apply network technology, on the other hand, we should have good consciousness, be sensitive to political thought, and ${ }^{[5]}$ better implement teaching.

\section{Conclusion}

In the new era, the Internet is getting deeper into schools, and the online media is thriving. Therefore, in ideological and political education, both higher vocational schools and ideological and political teachers should explore new ways to improve the previous mode of ideological and political education, and do a good job in guiding network public opinion, so that ideological and political education can form a new situation. Optimize effect of education.

\section{References}

[1] Guo Zefeng. Challenges and Countermeasures of Ideological and Political Education for Higher Vocational Students under J]. New Media Environment Chinese character culture ,2018,22:76-77.

[2] Chen Hong. J]. of Network Ideological and Political Education in Higher Vocational Colleges under Weibo Environment Chinese Journal of Multimedia and Network Teaching (Chinese Journal)12:116-117.

[3] Liu Yihong. Existing Problems and Promotion Strategies of National Identity Education for Higher Vocational Students from the Perspective of J]. Media Journal of Ningbo Vocational and Technical College.

[4] Song Qi. A Study on Ideological and Political Education of Apartments in Higher Vocational Colleges under the New Media Environment [D].]; and East China Normal University 2014.

[5] Li Xuewei. A Study on the Hidden Education of Ideological and Political Work in Higher Vocational Colleges under J]. New Media Environment Liaoning economy ,2020,10:80-81. 